\title{
Post-Synthetic Coordination Modification of Robust Pillared- Rod Metal-Azolate Frameworks for Diversified Applications
}

\author{
${ }^{a}$ MOE Key Laboratory of Bioinorganic and Synthetic Chemistry, School of Chemistry, Sun Yat-Sen \\ University, Guangzhou 510275, China \\ ${ }^{\mathrm{b}}$ School of Biotechnology and Health Science, Wuyi University, Jiangmen 529000, Guangdong, China \\ Pei-Qin Liao and Xiao-Ming Chen*,a,b
}

Received, March 9, 2021; Accepted, April 22, 2021; Published, May 31, 2021

\begin{abstract}
Post-synthetic coordination modification has proven to be a general and powerful approach for the functionalization of porous coordination polymers or metal-organic frameworks (MOFs). Metal-azolate frameworks (MAFs) are an important subclass of MOFs. In this account, the progress in the coordination post-synthetic modifications of an exceptionally robust pillared-rod MAF, featuring mixed $\mu$-chloride and $\mu_{3}$-triazolate bridges as the rods and linear bistriazolates as the pillars, and its structural analogues with different transition metal ions and/or expanded organic bridging ligands are summarized and discussed. Through removal of the terminal coordinated solvent molecules, redox of the metal ions, and exchange of the anionic inorganic bridging ligands in the rods, significantly enhanced performances can be realized in carbon dioxide capture, photocatalytic carbon dioxide reduction, photocatalytic hydrogen generation, electrolytic water oxidation and oxidation of ethylbenzene.
\end{abstract}

\section{Introduction}

In the past three decades, porous coordination polymers (PCPs), ${ }^{1}$ also more well known as metal-organic frameworks (MOFs), ${ }^{2}$ have been very extensively investigated for the interesting structures and properties, especially relevant with their porous structures. Porous metal-azolate frameworks (MAFs) are an important subclass of PCPs or MOFs based on azolates (deprotonated poly-nitrogen-containing fivemembered heterocycles), such as imidazolates, pyrazolates, triazolates and tetrazolates, as well as their derivatives as bridging ligands. ${ }^{3}$ Azolate ligands have strong coordination ability for transition metal ions. Besides, they could combine the negative charge of carboxylate ligands and the predictable coordination behavior of pyridine ligands. These characteristics are not only helpful to predict and control the local coordination geometries and overall network topologies of MOFs, but also help to construct functional materials with high thermal and chemical stabilities. ${ }^{4-7}$

Post-synthetic modification (PSM) is the subsequent chemical modification of a synthesized framework in a

Corresponding Author: Xiao-Ming Chen

Address: MOE Key Laboratory of Bioinorganic and Synthetic Chemistry, School of Chemistry, Sun Yat-Sen University, Guangzhou 510275, China

Tel: +862084112074

E-mail: cxm@mail.sysu.edu.cn

Keywords: metal-azolate framework, post-synthetic modification, adsorption, catalysis, bistriazolate, metal-organic framework, coordination polymer heterogeneous manner after the formation of solid lattices rather than a direct generation from functionalized ligands or metal ions. ${ }^{8-11}$ This very useful and powerful method has become quite popular, and has led to the generations of many MOFs with improved gas adsorption, catalysis and other performances. ${ }^{8,12-16}$ PSM can be restricted to modifications on the organic ligands of the frameworks without significant perturbation of the coordination spheres. For instance, the bridging btm $^{2-}\left(\mathrm{H}_{2} \mathrm{btm}=\operatorname{bis}(5-\right.$ methyl-1H-1,2,4-triazol-3yl)methane) ligands in the frameworks of some MAFs can be oxidized into btk ${ }^{2-}\left(\mathrm{H}_{2} \mathrm{btk}=\right.$ bis(5-methyl-1,2,4-triazol-3yl)methanone) to alter the framework flexibilities and pore surface properties for drastic enhancement of carbon dioxide/ methane or propylene/propane adsorption selectivity. ${ }^{12,17}$ Such kind of PSM is only limited to a few MOFs (including MAFs) with easily modifiable organic ligands. Coordination modifications are another sort of PSM, which were more frequently reported, because metal-ligand coordination bonds are usually labile and changeable under relatively mild conditions. Such modifications usually refer to capture/release of metal ions and ligands, exchange of metal ions, changes of the valence state of metal ions and inorganic/organic bridging ligands on the coordination frameworks. ${ }^{11}$ In this account, we will review the investigations on the coordination modifications of a MAF, namely $\left[\mathrm{Mn}_{2} \mathrm{Cl}_{2}(\right.$ bbta $\left.)\left(\mathrm{H}_{2} \mathrm{O}\right)_{2}\right]$ (MAF$\mathrm{X} 25-\mathrm{Cl}, \mathrm{H}_{2} \mathrm{bbta}=1 H, 5 H$-benzo(1,2-d:4,5-d')bistriazole, see Fig. 1a) ${ }^{18}$ and its structural analogues $\left(\left[\mathrm{Fe}_{2} \mathrm{Cl}_{2}(\mathrm{bbta})\left(\mathrm{H}_{2} \mathrm{O}\right)_{2}\right]\right.$ 
(a)<smiles>c1cc2nn[nH]c2cc2n3c(cc4nn[nH]c4cc1-2)Oc1cc2nn[nH]c2cc1N3</smiles>

(b)
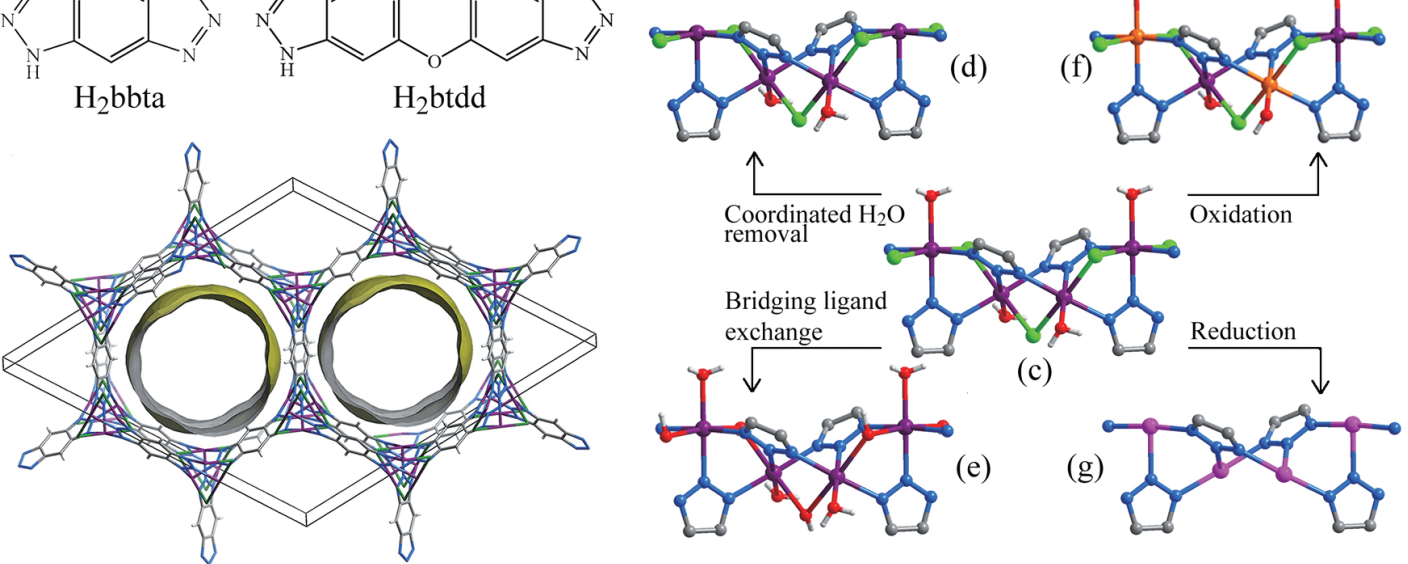

Fig. 1 (a) Structures of the bistriazole ligands. (b) The 3D network of guest-free MAF-X25-Cl. (c) The helical chain fragment in MAF-X25$\mathrm{Cl}$. PSMs of the helical chains in MAF-X25-Cl and its analogous MAFs, including (d) removal of terminal coordinated solvent molecule, (e) exchange of the bridging chloride ligands with hydroxide ligands, and (f-g) oxidation/reduction of metal(II) ions into metal(III)/metal(I) ions (C, gray; $\mathrm{H}$, light gray; $\mathrm{Cl}$, green; $\mathrm{N}$, blue; $\mathrm{O}$, red; $\mathrm{M}(\mathrm{II})$, purple; $\mathrm{M}(\mathrm{III})$, orange; $\mathrm{M}(\mathrm{I})$, pink).

(MAF-X26-Cl), $\left[\mathrm{Co}_{2} \mathrm{Cl}_{2}(\mathrm{bbta})\left(\mathrm{H}_{2} \mathrm{O}\right)_{2}\right]$ ( $\left.\mathrm{MAF}-\mathrm{X} 27-\mathrm{Cl}\right)$, $\left[\mathrm{Ni}_{2} \mathrm{Cl}_{2}(\right.$ bbta $\left.)\left(\mathrm{H}_{2} \mathrm{O}\right)_{2}\right](\mathrm{MAF}-\mathrm{X} 28-\mathrm{Cl})$ and $\left[\mathrm{Cu}_{2} \mathrm{Cl}_{2}(\right.$ bbta $\left.)\left(\mathrm{H}_{2} \mathrm{O}\right)_{2}\right]$ (MAF-X29-Cl)) as examples to illustrate the important roles of PSMs for enhanced performances of MOFs in absorption and catalysis.

Thanks to the exceptionally robust and stable characters, many MAFs can be chemically modified by coordination PSM on the metal ions and/or the ligands. Particularly, MAF$\mathrm{X} 25-\mathrm{Cl}$ is a very robust MAF, which features a pillaredrod three-dimensional (3D) structure with a honeycomb network along the $c$ direction (Fig. 1b). ${ }^{18}$ Each bbta ${ }^{2-}$ ligand coordinates to six $\mathrm{Mn}(\mathrm{II})$ ions, and each $\mathrm{Mn}(\mathrm{II})$ is coordinated in a distorted octahedral fashion by three nitrogen atoms from three $\mu_{3}-\mathrm{bbta}^{2-}$ ligands, two $\mu-\mathrm{Cl}^{-}$anions and one terminal $\mathrm{H}_{2} \mathrm{O}$ molecule. Each pair of $\mathrm{Mn}(\mathrm{II})$ ions are bridged by two triazolate groups and a $\mu-\mathrm{Cl}^{-}(\mathrm{Mn} \cdots \mathrm{Mn} 3.6885(7) \AA)$ to form a helical rod (Fig. 1c), which are further pillared by the organic bbta $^{2-}$ ligands into a 3D network. Microcrystalline Fe(II), $\mathrm{Co}(\mathrm{II}), \mathrm{Ni}(\mathrm{II})$, and $\mathrm{Cu}(\mathrm{II})$ analogues of MAF-X25-Cl can be also synthesized under similar reaction conditions. By virtue of coordination PSM methods, we and other groups achieved significantly improved performances of the MAF-X25-Cl and its structural analogues with different transition metal ions and organic ligands in gas adsorption and catalysis. The PSMs include removal of the terminal coordinated solvent molecules, oxidation/reduction of metal(II) into metal(III)/ metal(I), exchange of the bridging chloride ligands with hydroxide and bromide ligands in the rods (Fig. 1d-g). Such PSMs led to very significant enhancements on the catalysis and gas separation performances of the MAFs, which will be briefly summarized and discussed in the following sections.

\section{Removal of the terminal coordinated solvent molecules}

When water and small organic solvent molecules act as terminal ligands, they are usually labile. The removal of such coordinated solvent molecules in MOFs is actually the simplest PSM approach, ${ }^{8}$ which provides open metal sites (OMSs) as strong binding sites for absorption of $\mathrm{CO}_{2}$ and other polar and even non-polar gas molecules. Taking our MAF-X25-Cl as an example, after heating at $180{ }^{\circ} \mathrm{C}$ under vacuum, the terminal $\mathrm{H}_{2} \mathrm{O}$ molecules in this MAF can be easily removed. The guest-free MAF-X25-Cl can retain its pillared-rod structure and single-crystallinity for X-ray diffraction due the exceptional robustness of the framework, and has large effective 1D channels $(d=1.1 \mathrm{~nm})$ parallel to the helical chains. On the pore surface of the 1D channel, there is a high density of open coordination sites in squarepyramidal coordination fashion (Fig. 1d). Owing to such strong binding sites, MAF-X25-Cl has a $\mathrm{CO}_{2}$ uptake of 5.36 $\mathrm{mmol} \mathrm{g}^{-1}$ at $298 \mathrm{~K}$ and 1 bar, which is a relatively high value in the previous study. ${ }^{19}$

Similarly, upon removal of the terminal water ligands, MAF-X26-Cl, an analogous material of MAF-X25-Cl, has open $\mathrm{Fe}(\mathrm{II})$ sites, which can undergo a cooperative spin transition above a threshold CO pressure and give stepwise adsorption isotherms at elevated temperatures. ${ }^{20}$ In-situ powder X-ray diffraction (PXRD) study revealed the $\mathrm{Fe}-\mathrm{C}_{\mathrm{CO}}$ bond length of 1.76(4) $\AA$ and a nearly linear Fe-C-O bond angle, demonstrating low-spin $\mathrm{Fe}$ (II) ions in $\left[\mathrm{Fe}_{2} \mathrm{Cl}_{2}\right.$ (bbta) $\left.(\mathrm{CO})_{2}\right]$. Such a strong binding for $\mathrm{CO}$ leads to a high adsorption enthalpy of $-66 \mathrm{~kJ} \mathrm{~mol}^{-1}$. In fact, MAFs with such OMSs can also be used to bind other molecules with coordinative ability. For instance, as analogous materials of 
MAF-X25-Cl, MAF-X27-Cl, MAF-X28-Cl, and MAF-X29$\mathrm{Cl}$ can capture large amounts of $\mathrm{NH}_{3}$, i.e. $17.95,14.68$, and $19.79 \mathrm{mmol} \mathrm{g}^{-1}$ at 1 bar and $298 \mathrm{~K}$, respectively, ${ }^{21-22}$ being attributed to their strong Lewis acidity and high density of the OMSs. Notably, the $\mathrm{NH}_{3}$ adsorption capacity of MAF-X29$\mathrm{Cl}$ was the highest among those reported for MOF-based $\mathrm{NH}_{3}$ adsorbents.

\section{Changing the valence state of metal ions}

\subsection{Oxidation of $\mathrm{Mn}(\mathrm{II})$ into $\mathrm{Mn}(\mathrm{III})$}

When the valence state of metal ions in a MOF is variable, it may possibly be tuned via PSM reduction or oxidation. Such PSM modification is usually much more drastic and difficult to retain the framework structure compared with the removal of terminal solvent ligands in a MOF. Therefore, only very robust MOFs with variable valence metal ions can be modified in this way. We found that, with a very robust pillared-rod framework, the exposed $\mathrm{Mn}$ (II) ions of MAF$\mathrm{X} 25-\mathrm{Cl}$ can be partially oxidized by $\mathrm{H}_{2} \mathrm{O}_{2}$ to form an oxidized MAF, namely $\left[\mathrm{Mn}^{\mathrm{II}} \mathrm{Mn}^{\mathrm{III}}(\mathrm{OH}) \mathrm{Cl}_{2}\right.$ (bbta)] (MAF-X25ox$\mathrm{Cl}$ ), under alkaline condition (Fig. 1e), ${ }^{18}$ which was the first example of a MOF with Mn(III) ions. Rietveld refinement of the PXRD pattern shows that the $\mathrm{Mn}(\mathrm{III})$ is coordinated by three nitrogen atoms from three bbta $^{2-}$ ligands, two $\mu-\mathrm{Cl}^{-}$ anions and one monodentate hydroxide (Fig. 1f). In contrast, the analogous material $\left[\mathrm{Mn}_{2}(\mathrm{dobdc})\left(\mathrm{H}_{2} \mathrm{O}\right)_{2}\right]$ constructed by the carboxylate ligands becomes amorphous under the similar oxidation condition. These observations imply that, the nitrogen-rich and more stable bistriazolate ligand may play an critical role in stabilizing the $\mathrm{Mn}(\mathrm{III})$ ions in MAF$\mathrm{X} 25 \mathrm{ox}-\mathrm{Cl}$. Also notably, without protection of macrocyclic or polydentate chelating ligands, such as a porphyrinate, the $\mathrm{Mn}(\mathrm{III})$ ion is usually unstable in solution, thus it is actually not feasible to directly synthesize a MOF with Mn(III) active sites in the absence of protecting macrocyclic or polydentate chelating ligand. Therefore, post-oxidation of $\mathrm{Mn}(\mathrm{II})$ ions within the frameworks represents a crucial and effective method to obtain $\mathrm{Mn}$ (III) ion-containing MOFs.

The coordination environment of each Mn(III) ion in MAF-X25ox-Cl is similar to those of the well-known $\mathrm{Mn}^{\mathrm{III}}-$ porphyrinate species. Therefore, we studied the catalytic oxidation performance of this MAF for oxidation of ethylbenzene (EB) into acetophenone by using tert-butyl hydroperoxide (TBHP) as the oxidant. MAF-X25ox-Cl exhibits high catalytic activity with the selectivity of $>99 \%$ and turnover frequency (TOF) of $118 \mathrm{~h}^{-1}$ (Fig. 2), which is a much higher catalytic performance than those of $\mathrm{Mn}$ (II)- based MAF-X25-Cl and the excellent homogeneous catalyst [Mn(TPP)Cl] $\left(\mathrm{H}_{2} \mathrm{TPP}=5,10,15,20\right.$-tetraphenylporphyrin $)$. These results indicate that the high catalytical performance should be ascribed to the Mn(III) ions. Meanwhile, oxygen gas, as the greenest oxidant, can be used to replace the strong organic oxidant TBHP, though the catalytic performance is worse in terms of selectivity and conversion rate (Fig. 2). Furthermore, when diphenylmethane as a larger substrate was used, the catalytic oxidation activity became very poor, implying that it cannot access the internal pores and the catalytic reactions mainly occur on the outer crystal surfaces.

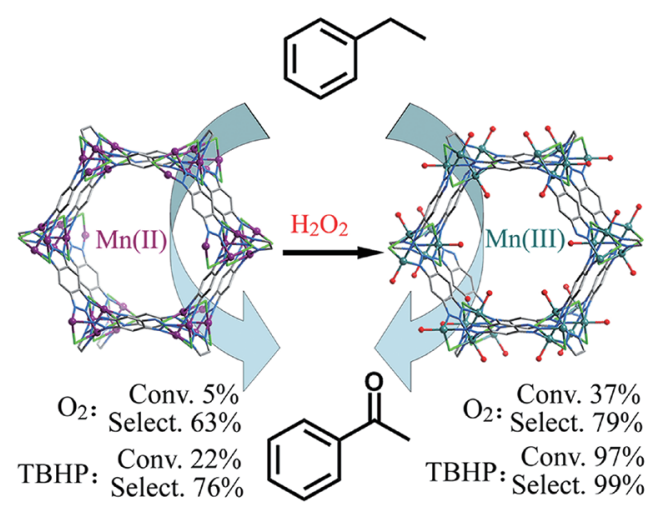

Fig. 2 Comparison of the activities of MAF-X25-Cl and MAF$\mathrm{X} 250 \mathrm{x}-\mathrm{Cl}$ for catalytic oxidation of ethylbenzene. Adapted from Ref. 18.

\subsection{Oxidation of Co(II) into Co(III)}

Capturing $\mathrm{CO}_{2}$ under humid conditions is a great challenge. Although many porous materials can capture large amounts of $\mathrm{CO}_{2}$ under dry conditions, the capture capacity is significantly reduced in the presence of water, since water molecules strongly compete for binding sites or destroy the skeleton. The monodentate hydroxide is the key active site of carbonic anhydrase, which can greatly accelerate the conversion between $\mathrm{CO}_{2}$ and $\mathrm{HCO}_{3}^{-}$in an aqueous environment. Thus, a porous material with monodentate hydroxides may be a very good candidate for capturing $\mathrm{CO}_{2}$ under humid conditions.

As being mentioned in Section 3.1, the post-synthetic oxidized MAF, MAF-X25ox-Cl, has monodentate hydroxide groups on the pore surface, we then studied the $\mathrm{CO}_{2}$ capture performances of MAF-X25ox-Cl and its cobalt analogue $\left[\mathrm{Co}^{\mathrm{II}} \mathrm{Co}^{\mathrm{III}}(\mathrm{OH}) \mathrm{Cl}_{2}\right.$ (bbta)] (MAF-X27ox-Cl) under humid conditions, in which the cobalt MAF was synthesized by using the similar post-oxidation treatment for MAF-X25ox-Cl (Fig. 1f). With the presence of the monodentate hydroxide groups on the pore surfaces, the $\mathrm{CO}_{2}$ capture performances of both MAF-X25ox-Cl and MAF-X27ox-Cl are much higher than those of MAF-X25-Cl and MAF-X27-Cl, and even higher than most porous materials. ${ }^{19}$ Specifically, MAF-X27ox-Cl showed 
the highest $\mathrm{CO}_{2}$ adsorption enthalpy $\left(124 \mathrm{~kJ} \mathrm{~mol}^{-1}\right)$ and uptake $\left(9.1 \mathrm{mmol} \mathrm{cm} \mathrm{cm}^{-3} 298 \mathrm{~K}\right.$ and 1 bar $), \mathrm{CO}_{2} / \mathrm{N}_{2}$ selectivity (262 at $298 \mathrm{~K})$, as well as very good recycling stability and fast $\mathrm{CO}_{2}$ adsorption/desorption kinetics. In-situ infrared (IR) spectra demonstrated that the reaction of $\mathrm{OH}^{-}+\mathrm{CO}_{2}=\mathrm{HCO}_{3}$ is reversible during the $\mathrm{CO}_{2}$ adsorption/desorption, which is very similar to the $\mathrm{CO}_{2}$ binding mechanism of carbonic anhydrase mentioned in the previous section (Fig. 3) for capturing and transportation of $\mathrm{CO}_{2}$ in biological systems. Similar phenomena were latter observed in other MOFs systems. ${ }^{23-24}$ Through the gas breakthrough experiments, we demonstrated that MAF-X27ox-Cl has a very fast sorption kinetics and an ultrahigh working capacity for capturing $\mathrm{CO}_{2}$
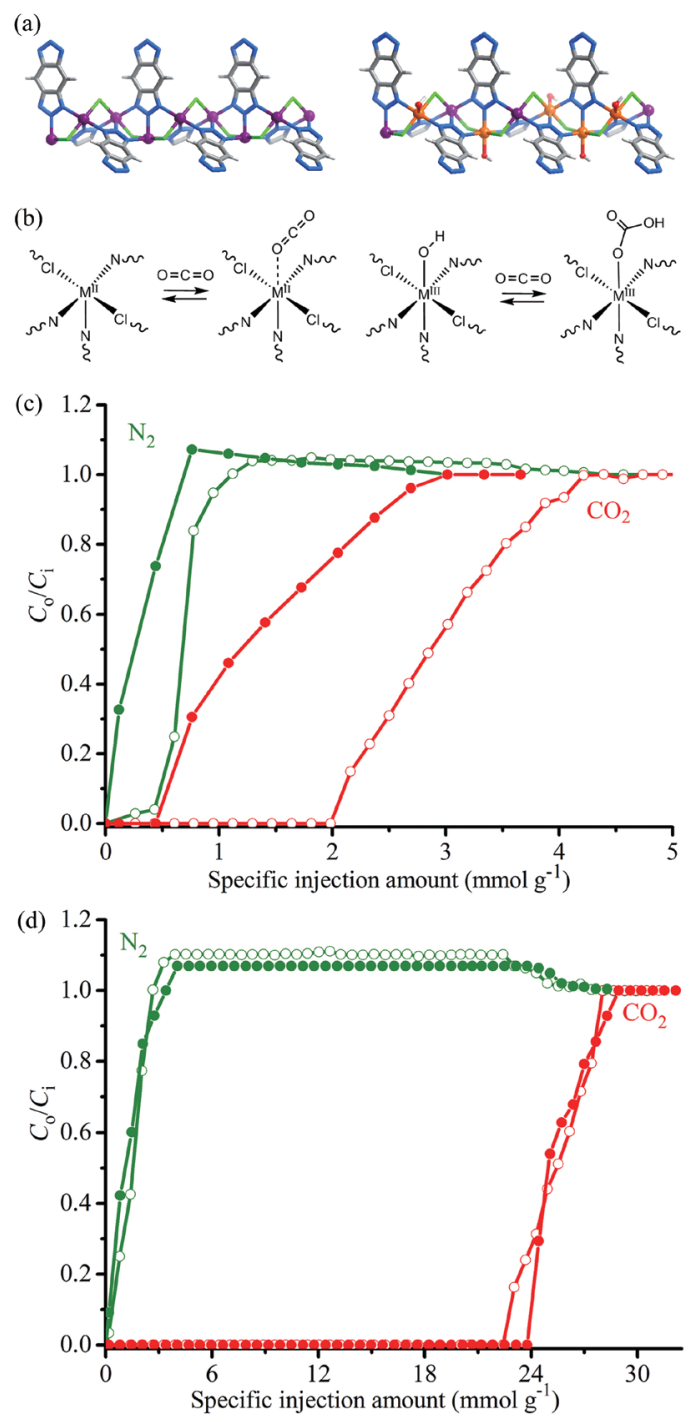

Fig. 3 Comparison of the local framework structures (a) before and after oxidative PSM (C, gray; $\mathrm{H}$, light gray; $\mathrm{Cl}$, green; $\mathrm{N}$, blue; $\mathrm{O}$, red; $\mathrm{M}(\mathrm{II})$, purple; $\mathrm{M}(\mathrm{III})$ orange). $\mathrm{CO}_{2}$ adsorption mechanisms (b) of MAF-X25/MAF-X27 and MAF-X25ox-CI/MAF-X27ox-Cl. Breakthrough curves for $10: 90 \mathrm{CO}_{2} / \mathrm{N}_{2}(\mathrm{v} / \mathrm{v})$ mixture with $0 \%$ (open) and $82(3) \%$ relative humidity (solid) at $313 \mathrm{~K}$ and 1 bar passing through a column packed by microcrystalline (c) MAF-X27-Cl or (d) MAF-X27ox-Cl. Lines are drawn to guide eyes. $C_{i}$ and $C_{o}$ are the concentrations of each gas at the inlet and outlet, respectively. Adapted from Ref. 19. from flue gas at $313 \mathrm{~K}$, even in the presence of high relative humidity (83\%), highlighting the suitability of MAF-X27ox$\mathrm{Cl}$ as a promising $\mathrm{CO}_{2}$ capture adsorbent. It should be noted that it is difficult to introduce the monodentate hydroxide into the porous materials, because the hydroxide ligands strongly tend to form bidentate or tridentate coordination in their metal compounds, indicating the importance of this PSM approach. In fact, MAF-X25ox-Cl and MAF-X27ox-Cl represented the first examples of monodentate hydroxide-containing MOFs and showed exceptionally high $\mathrm{CO}_{2}$ capture performances and stabilities under high humid conditions.

\subsection{In-situ reduction of $\mathrm{Cu}(\mathrm{II})$ into $\mathrm{Cu}(\mathrm{I})$}

Besides the oxidative PSM discussed above, reductive PSM is also possible for some MOFs. Recently, we found that the $\mathrm{Cu}$ (II) ions in MAF-X29-Cl can be in-situ reduced into $\mathrm{Cu}(\mathrm{I})$ ions during photodriven hydrogen evolution reaction. ${ }^{25}$ The catalytic activity of MAF-X29-Cl was evaluated under visible light $(\lambda>420 \mathrm{~nm})$ in water/acetonitrile $(v / v, 25: 65)$ with $\left[\mathrm{Ru}(\text { bpy })_{3}\right] \mathrm{Cl}_{2}$ (bpy $=2,2^{\prime}$-bipyridine) as a photosensitizer and triethanolamine (TEOA) as a sacrificial agent. Interestingly, the $\mathrm{H}_{2}$ production rate was slow initially and then became fast and fast, and finally reached $101.4 \mathrm{mmol} \mathrm{g}^{-1} \mathrm{~h}^{-1}$, which is much higher than that for the as-synthesized sample (4.6 mmol $\left.\mathrm{g}^{-1} \mathrm{~h}^{-1}\right)$. The in-situ electron paramagnetic resonance (EPR) spectroscopy showed that the EPR signals $\left(g_{\|}=2.28\right.$ and $g_{\perp}=$ 2.09) assigned to $\mathrm{Cu}$ (II) species become weaken gradually and disappear eventually, demonstrating the generation of $\mathrm{Cu}(\mathrm{I})$ species. After hydrogen evolution experiment, the catalyst was recovered and its PXRD pattern was very similar to that of the as-synthesized sample. Based on the EPR spectroscopy, Raman spectra and PXRD pattern, it can be concluded that during the hydrogen evolution, MAF-X29-Cl had been turned into a $\mathrm{Cu}(\mathrm{I})$-based $\left[\mathrm{Cu}_{2}\right.$ (bbta) $]$ (MAF-29), which was the actual photocatalyst. As a result of the reduction of $\mathrm{Cu}$ (II) ions, the $\mu-\mathrm{Cl}^{-}$ligands were free from the rod for the charge compensation of the framework, each $\mathrm{Cu}(\mathrm{I})$ ion in MAF-29 is coordinated in a $T$-shaped fashion by three nitrogen atoms from three bbta ${ }^{2-}$ ligands (Fig. 1g). The photodriven hydrogen evolution experiment for MAF-29 was measured under the same reaction conditions. As expected, the initial production rate for $\mathrm{H}_{2}$ was $102.8 \mathrm{mmol} \mathrm{g}^{-1} \mathrm{~h}^{-1}$, which is very close to that of MAF-X29-Cl after a hydrogen evolution experiment for $3 \mathrm{~h}$ (Fig. 4). Importantly, the performance of MAF-29 is not only higher than those of most other catalysts, but also higher than those of most Pt decorated catalysts. The synergistic catalysis of two adjacent $\mathrm{Cu}(\mathrm{I})$ ions within MAF-29 for the reduction of $\mathrm{H}_{2} \mathrm{O}$ to $\mathrm{H}_{2}$ was investigated at molecular level by 
density functional theory (DFT) calculations. Compared to the $\mathrm{Cu}$-based catalysts with single metal catalytic centers, MAF29 has a very low energy barrier for water dissociation due to the synergistic catalysis of two adjacent $\mathrm{Cu}(\mathrm{I})$ ions, that is, one serves as a catalytic center to bind and activate the $\mathrm{H}_{2} \mathrm{O}$ molecule while the other acts as an assistant catalytic site to facilitate the $\mathrm{HO}-\mathrm{H}$ bond breaking.
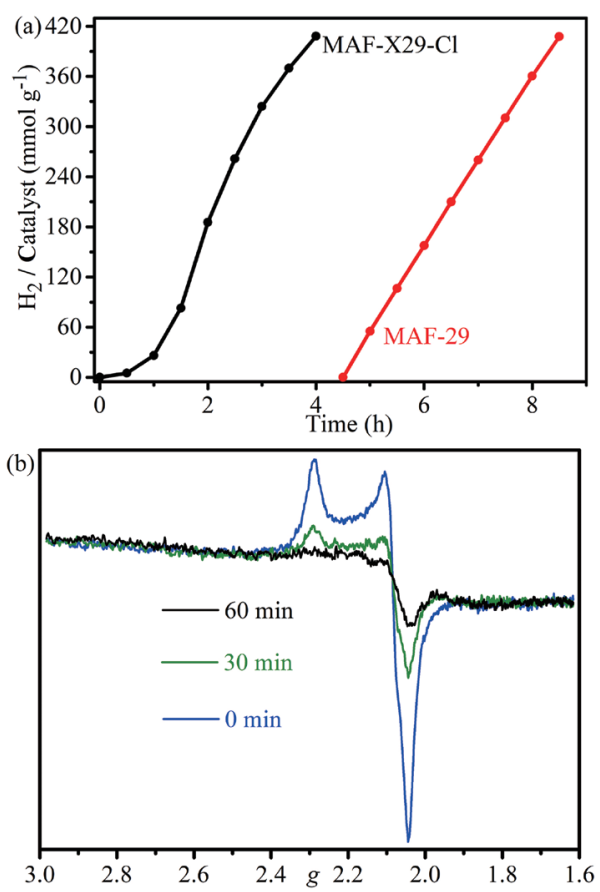

Fig. 4 (a) The photodriven hydrogen-production rates of MAFX29-Cl (black) and MAF-29 (red). (b) in-situ EPR spectra of MAF$\mathrm{X} 29-\mathrm{Cl}$ measured before (blue) and after photodriven hydrogen evolution reaction for 30 (green) and 60 (black) min, respectively. Adapted from Ref. 25.

\section{Exchange of the anionic inorganic bridging ligand}

Considering that the redox property of the Co(II) ions of MAF-X27 is beneficial to the oxygen evolution reaction (OER), and there is a high-concentration $\left(5.88 \mathrm{mmol} \mathrm{g}^{-1}\right.$, $6.69 \mathrm{mmol} \mathrm{cm}^{-3}$ ) of square-pyramidal $\mathrm{Co}$ (II) ions, each with an open coordination site exposed on the pore surface, we studied the OER property of MAF-X27-Cl in $1.0 \mathrm{M}$ $\mathrm{KOH}$ solution. ${ }^{26}$ Interestingly, by repeating the linear sweep voltammetry (LSV), the OER performance become better, and finally reached a $\eta_{10}$ of $387 \mathrm{mV}$, being $121 \mathrm{mV}$ lower than for the as-synthesized sample (Fig. 5). By virtue of Rietveld refinement of PXRD, Raman spectroscopy and XPS analyses, we found that the $\mu-\mathrm{Cl}^{-}$ligands in the rods of MAF-X27-Cl were replaced by $\mu-\mathrm{OH}^{-}$ions to form a new MAF $\left[\mathrm{Co}_{2}(\mu-\mathrm{OH})_{2}\right.$ (bbta) $](\mathrm{MAF}-\mathrm{X} 27-\mathrm{OH})$ (Fig. 1e). To more accurately evaluate the OER activity of MAF-X27-
$\mathrm{OH}$, we fabricated the electrode consisting of MAF-X27-Cl firmly attached on the metal surface (denoted as MAF-X27$\mathrm{Cl}(\mathrm{Cu})$ ) by growing the MAF-X27-Cl crystals directly on $\mathrm{Cu}$ foil. After ion exchange treatment of MAF-X27-Cl(Cu), the electrode MAF-X27-OH(Cu) was obtained. In $1.0 \mathrm{M}$ $\mathrm{KOH}$ solution, MAF-X27-OH(Cu) gives much improved OER performances with overpotential as low as $292 \mathrm{mV}$ at $10 \mathrm{~mA} \mathrm{~cm}^{-2}$ and turnover frequency (TOF) up to $0.019 / 0.25$ $\mathrm{s}^{-1}$ at overpotentials of $300 / 400 \mathrm{mV}$. Notably, MAF-X27$\mathrm{OH}(\mathrm{Cu})$ showed a markedly better catalytic activity than those of the conventional OER catalysts $\mathrm{Co}(\mathrm{OH})_{2}(421$ $\mathrm{mV})$ and $\mathrm{Co}_{3} \mathrm{O}_{4}(445 \mathrm{mV})$ directly grown on carbon cloth substrates. Furthermore, cyclic voltammetry curves, LSV curves, PXRD patterns, and SEM images of MAF-X27$\mathrm{OH}$ showed negligible changes after the electrolysis for 24 h. At $\mathrm{pH}=7$, MAF-X27-Cl can be completely stable in the absence of ion exchange. At $\mathrm{pH}=7$, MAF-X27-OH exhibited a better OER activity $\left(\eta_{2}\right.$ of $\left.489 \mathrm{mV}\right)$ than that of MAF-X27$\mathrm{Cl}$ (a current density of $0.028 \mathrm{~mA} \mathrm{~cm}^{-2}$ at a $\eta_{10}=$ of $570 \mathrm{mV}$ ), which unambiguously demonstrates the effectiveness of the $\mu-\mathrm{OH}^{-}$ligand (Fig. 5). Using an isotope tracing technique, we found the high catalytical performance of MAF-X27-OH is attributed to the directly participation of the coordinated $\mathrm{OH}^{-}$ ligands in the formation of $\mathrm{O}_{2}$, which provides a low-energy intraframework coupling pathway in the OER process (Fig. $5 b)$. MAF-X27-OH was the first example of azolate-based MOFs showing a high OER performance and stability, which demonstrates the suitability of such MOFs as OER catalysts.

More interestingly, the presence of bridging hydroxy ligands in the framework of a MAF not only can enhance the OER through the direct participation, but also can render a stronger binding ability to $\mathrm{CO}_{2}$ molecule, and hence remarkably promote the photocatalytic $\mathrm{CO}_{2}$ reduction. By comparing the photocatalytic activities of a series of cobalt-based MOFs possessing different coordination environments, we recently demonstrated that the $\mu-\mathrm{OH}^{-}$ ligands in MAF-X27-OH can provide a synergistic effect of the microenvironment of open metal centers to remarkably promote the photocatalytic activity for $\mathrm{CO}_{2}$ reduction. ${ }^{27}$ For comparison, three isostructural honeycomb-like $\mathrm{Co}(\mathrm{II})$-based MOFs, namely MAF-X27-C1, MAF-X27-OH and MOF74-Co), were used for photocatalytic $\mathrm{CO}_{2}$ reduction. The photocatalytic $\mathrm{CO}_{2}$ reduction performances of the these Cobased MOFs were studied under visible light in pure $\mathrm{CO}_{2}$ at 1.0 bar in $4: 1 \mathrm{CH}_{3} \mathrm{CN} / \mathrm{H}_{2} \mathrm{O}$ mixed solvent for $10 \mathrm{~h}$, using $\left[\mathrm{Ru}(\mathrm{bpy})_{3}\right] \mathrm{Cl}_{2}$ as the photosensitizer. Obviously, the catalytic performance of MAF-X27-OH with the TOF of $28 \times 10^{-3}$ $\mathrm{s}^{-1}$ and selectivity of $97.2 \%$ is much higher than those of 
MOF-74-Co $\left(\mathrm{TOF}=13 \times 10^{-3} \mathrm{~s}^{-1}\right.$, selectivity $\left.=63.6 \%\right)$ and MAF-X27-Cl $\left(\mathrm{TOF}=6.3 \times 10^{-3} \mathrm{~s}^{-1}\right.$, selectivity $\left.=58.8 \%\right)$, indicating the importance of the $\mu-\mathrm{OH}^{-}$ligands (Fig. 6a). More attractively, when the $\mathrm{CO}_{2}$ partial pressure was reduced to 0.1 bar, only MAF-X27-OH exhibited a high CO TOF of $23 \times 10^{-3} \mathrm{~s}^{-1}$ with an unchanged CO selectivity of $97.2 \%$, comparable to the TOF $\left(28 \times 10^{-3} \mathrm{~s}^{-1}\right)$ under pure $\mathrm{CO}_{2}$. Also notably, the performance of MAF-X27-OH under 0.1 bar $\mathrm{CO}_{2}$ is even better than that of the best homogeneous catalyst (TOF of $19 \times 10^{-3} \mathrm{~s}^{-1}$, selectivity of $92 \%$ ) working under the same condition. MAF-X27-OH represents the first example of MOFs showing a high performance of the photocatalytic $\mathrm{CO}_{2}$ reduction under dilute $\mathrm{CO}_{2}$ atmosphere.
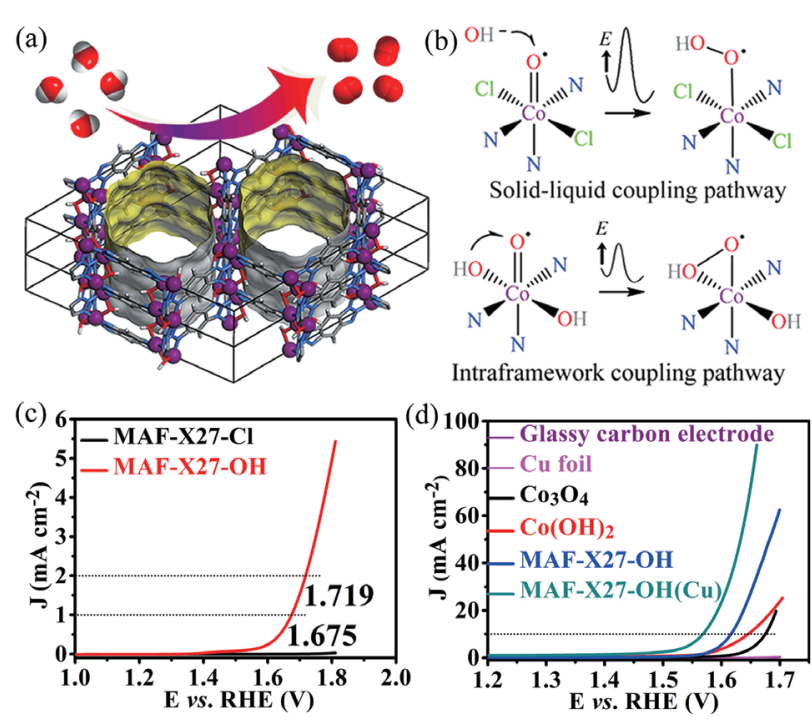

Intraframework coupling pathway

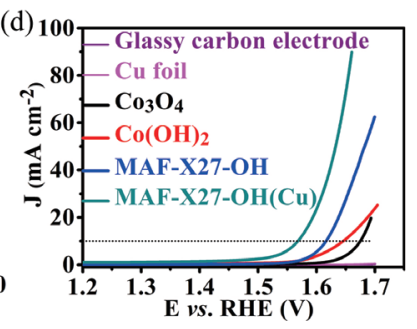

Fig. 5 (a) Framework and pore surface structure of MAF-X27$\mathrm{OH}$. (b) Solid-liquid coupling pathway for MAF-X27-Cl and intraframework coupling pathway for MAF-X27-OH. (c) LSV curves of MAF-X27-Cl and MAF-X27-OH at pH = 7. (d) LSV curves for electrodes modified by MAF-X27-OH or other related materials at $\mathrm{pH}=14$. Adapted from Ref. 26.

We studied the mechanism of this superb catalytic performance through periodic density functional theory (PDFT) calculations and isotope labeling, and revealed that, the $\mu$-OH ligands located at the cis-positions of the Co active site can form a pair of hydrogen bonds to stabilize the Co$\mathrm{CO}_{2}$ adduct and also act as the proton source in the reduction process (Fig. 6b). Thanks to such a pair of hydrogen bonds, the MAF-X27-OH binds $\mathrm{CO}_{2}$ more strongly than $\mathrm{H}_{2} \mathrm{O}$. The strong $\mathrm{CO}_{2}$ binding affinity can stabilize the initial $\mathrm{Co}-\mathrm{CO}_{2}$ adduct to promote the $\mathrm{CO}_{2}$ reduction, and a weak $\mathrm{H}_{2} \mathrm{O}$ binding affinity can suppress $\mathrm{H}_{2}$ (the byproduct) production and ensure a high CO selectivity. A similar phenomenon was latter observed for a Ni-based metal-organic framework. ${ }^{28}$
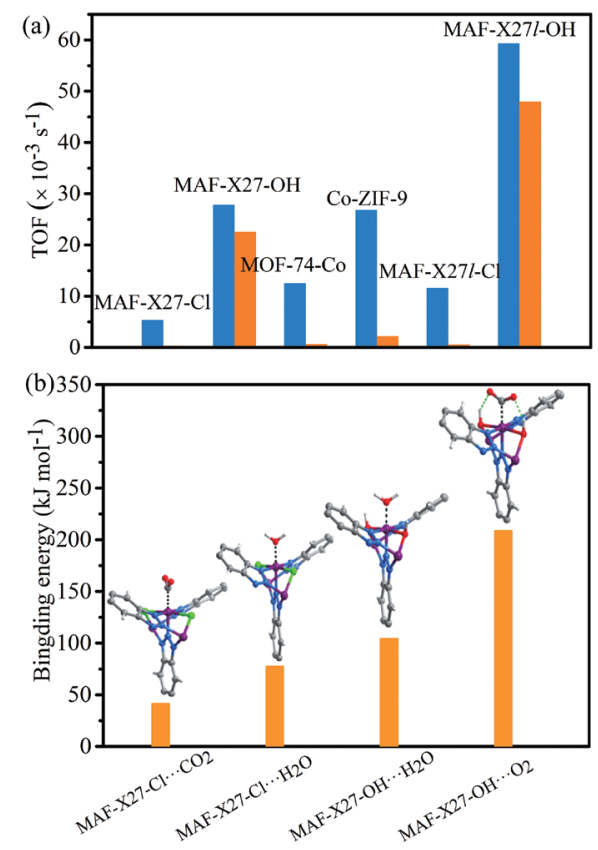

Fig. 6 (a) Comparison of the TOF values for the photo-catalytic reductions of $\mathrm{CO}_{2}$ to $\mathrm{CO}$ under $1.0 \mathrm{~atm}$ (blue) and $0.1 \mathrm{~atm}$ (orange). (b) Comparison of the $\mathrm{CO}_{2}$ and $\mathrm{H}_{2} \mathrm{O}$ binding structures and energies of the reduced forms of MAF-X27-Cl and MAF-X27OH. Adapted from Ref. 27.

Moreover, the photocatalytic $\mathrm{CO}_{2}$ reduction performance can be further improved by enlarging the pore size of the MAF. When bis(1H-1,2,3-triazolo-[4,5-b], [4', $\left.\left.5^{\prime}-i\right]\right)$ dibenzo[1,4]dioxin $\left(\mathrm{H}_{2} \text { btdd }\right)^{29}$ as an expanded version of the bridging ligand (Fig. 1a) is used to replace $\mathrm{H}_{2}$ bbta, $\left[\mathrm{Co}_{2}(\mu-\mathrm{Cl})_{2}(\mathrm{btdd})\right](\mathrm{MAF}-\mathrm{X} 27 \mathrm{l}-\mathrm{Cl})$ with larger pores can be obtained. Upon ion exchange treatment of MAF-X27l-Cl, $\left[\mathrm{Co}_{2}(\mu-\mathrm{OH})_{2}(\mathrm{btdd})\right](\mathrm{MAF}-\mathrm{X} 27 \mathrm{l}-\mathrm{OH})$ can be generated, which has a larger pore size ( $c a .2 .2 \mathrm{~nm}$ ) compared to MAF-X27$\mathrm{OH}(\mathrm{ca} .1 .1 \mathrm{~nm})$. Interestingly, in both 1.0 or $0.1 \mathrm{~atm} \mathrm{CO}_{2}$, the catalytic performances of MAF-X27l-OH are greatly better than those of MAF-X27-OH, as shown in Fig. 6a. Since the catalytic sites including the hydrogen bonding interactions of MAF-X27l-OH and MAF-X27-OH are basically the same, the higher catalytic activities of the expanded version can be ascribed to the larger pore size, which is beneficial for a quicker diffusion of the reactants/products.

Recently, Dincă et al. found that the $\mu-\mathrm{Cl}^{-}$bridges in $\left[\mathrm{Ni}_{2}(\mu-\mathrm{Cl})_{2}(\mathrm{btdd})\right]$ (MAF-X28l-Cl), a nickel analogue of MAF-X27l-Cl, can be exchanged by $\mu-\mathrm{Br}^{-}$to generate a new material $\left[\mathrm{Ni}_{2}(\mu-\mathrm{Br})_{2}\right.$ (btdd)] (MAF-X28l-Br). ${ }^{30}$ This PSM results in a slight pore shrinkage of $0.1 \mathrm{~nm}$, which shifts the water pore-filling step from a partial pressure of 0.32 to 0.24 . As a result, MAF-X28l-Br achieved a new record with the gravimetric water uptake of $0.64 \mathrm{~g} \mathrm{~g}^{-1}$ below $25 \%$ relative humidity, making it as a strong candidate for water harvesting under drought conditions. 


\section{Conclusion}

As shown above, the mixed organic and inorganic bridged helical rods in the robust pillared-rod MAFs are changeable and can be modified through removal of the terminal coordinated solvent molecules, redox reactions on the metal ions and exchanges of the inorganic bridging ligands. Although only a series of examples are known and summarized here, the results clearly demonstrate that, for robust and modifiable MAFs, PSM approaches provide important opportunities to functionalize and promote the performances of MAFs for diverse applications, such as carbon dioxide capture and catalysis, through optimizing the coordination environment of metal ions, the valence state of metal ions, as well as the microenvironment of the active sites.

\section{Acknowledgment}

This work was supported by the NSFC (21890380 and 21821003), Science and Technology Key Project of Guangdong Province (2020B010188002), Guangdong Natural Science Funds for Distinguished Young Scholar (2018B030306009).

\section{References}

1 B. F. Hoskins, R. Robson, J. Am. Chem. Soc. 1989, 111, 59625964.

2 S. R. Batten, N. R. Champness, X.-M. Chen, J. Garcia-Martinez, S. Kitagawa, L. Öhrström, M. O’Keeffe, M. Paik Suh, J. Reedijk, Pure Appl. Chem. 2013, 85, 1715-1724.

3 J.-P. Zhang, Y.-B. Zhang, J.-B. Lin, X.-M. Chen, Chem. Rev. 2012, $112,1001-1033$.

4 P.-Q. Liao, C.-T. He, D. D. Zhou, J.-P. Zhang, X.-M. Chen, Porous Metal Azolate Frameworks. In The Chemistry of Metal-Organic Frameworks, Wiley-VCH Verlag GmbH \& Co. KGaA: 2016; pp 309-343.

5 P.-Q. Liao, D.-D. Zhou, A.-X. Zhu, L. Jiang, R.-B. Lin, J.-P. Zhang, X.-M. Chen, J. Am. Chem. Soc. 2012, 134, 17380-17383.

6 P.-Q. Liao, W.-X. Zhang, J.-P. Zhang, X.-M. Chen, Nat. Commun. 2015, 6, 8697.

7 P.-Q. Liao, N.-Y. Huang, W.-X. Zhang, J.-P. Zhang, X.-M. Chen, Science 2017, 356, 1193-1196.

8 S. M. Cohen, Chem. Rev. 2012, 112, 970-1000.

9 K. K. Tanabe, S. M. Cohen, Chem. Soc. Rev. 2011, 40, 498-519.

10 Z. Wang, S. M. Cohen, Chem. Soc. Rev. 2009, 38, 1315-1329.

11 J.-P. Zhang, P.-Q. Liao, H.-L. Zhou, R.-B. Lin, X.-M. Chen, Chem. Soc. Rev. 2014, 43, 5789-5814.

12 P.-Q. Liao, A.-X. Zhu, W.-X. Zhang, J.-P. Zhang, X.-M. Chen, Nat. Commun. 2015, 6, 6350.

13 Z. Wang, S. M. Cohen, J. Am. Chem. Soc. 2007, 129, 1236812369 .

14 Z. Wang, S. M. Cohen, J. Am. Chem. Soc. 2009, 131, 1667516677.
15 T. Yamada, H. Kitagawa, J. Am. Chem. Soc. 2009, 131, 63126313.

16 H. Sato, R. Matsuda, K. Sugimoto, M. Takata, S. Kitagawa, Nat. Mater. 2010, 9, 661-666.

17 Y. Wang, N. Y. Huang, X. W. Zhang, H. He, R. K. Huang, Z. M. Ye, Y. Li, D. D. Zhou, P. Q. Liao, X. M. Chen, J. P. Zhang, Angew. Chem. Int. Ed. 2019, 58, 7692-7696.

18 P.-Q. Liao, X.-Y. Li, J. Bai, C.-T. He, D.-D. Zhou, W.-X. Zhang, J.-P. Zhang, X.-M. Chen, Chem. Eur. J. 2014, 20, 11303-11307.

19 P.-Q. Liao, H. Chen, D.-D. Zhou, S.-Y. Liu, C.-T. He, Z. Rui, H. Ji, J.-P. Zhang, X.-M. Chen, Energy Environ. Sci. 2015, 8, 10111016.

20 D. A. Reed, B. K. Keitz, J. Oktawiec, J. A. Mason, T. Runcevski, D. J. Xiao, L. E. Darago, V. Crocella, S. Bordiga, J. R. Long, Nature 2017, 550, 96-100.

21 A. J. Rieth, D. Dincă, J. Am. Chem. Soc. 2018, 140, 3461-3466.

22 A. J. Rieth, Y. Tulchinsky, M. Dincă, J. Am. Chem. Soc. 2016, 138, 9401-9404.

23 C. E. Bien, K. K. Chen, S.-C. Chien, B. R. Reiner, L.-C. Lin, C. R. Wade, W. S. W. Ho, J. Am. Chem. Soc. 2018, 140, 12662-12666.

24 A. M. Wright, Z. Wu, G. Zhang, J. L. Mancuso, R. J. Comito, R. W. Day, C. H. Hendon, J. T. Miller, M. Dincă, Chem 2018, 4, 2894-2901.

25 N.-Y. Huang, H. He, H. Li, P.-Q. Liao, X.-M. Chen, Chem. Commun. 2020, 56, 6700-6703.

26 X.-F. Lu, P.-Q. Liao, J.-W. Wang, J.-X. Wu, X.-W. Chen, C.-T. He, J.-P. Zhang, G.-R. Li, X.-M. Chen, J. Am. Chem. Soc. 2016, 138, 8336-8339.

27 Y. Wang, N.-Y. Huang, J.-Q. Shen, P.-Q. Liao, X.-M. Chen, J.-P. Zhang, J. Am. Chem. Soc. 2018, 140, 38-41.

28 B. Han, X. Ou, Z. Deng, Y. Song, C. Tian, H. Deng, Y.-J. Xu, Z. Lin, Angew. Chem. Int. Ed. 2018, 57, 16811-16815.

29 D. Denysenko, M. Grzywa, M. Tonigold, B. Streppel, I. Krkljus, M. Hirscher, E. Mugnaioli, U. Kolb, J. Hanss, D. Volkmer, Chem. Eur. J. 2011, 17, 1837-1848.

30 A. J. Rieth, A. M. Wright, G. Skorupskii, J. L. Mancuso, C. H Hendon, M. Dincă, J. Am. Chem. Soc. 2019, 141, 13858-13866. 


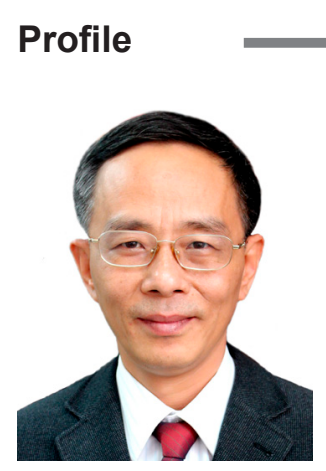

\section{Xiao-Ming Chen}

Xiao-Ming Chen was born and grew up in Guangdong, China, obtained his BSc in 1983 and MSc under the supervision of Prof. Hai-Fu Fan in 1986 at Sun Yat-Sen University (SYSU), and his PhD under the supervision of Prof. Thomas C. W. Mak at the Chinese University of Hong Kong in 1992. He then joined SYSU and became a professor in 1995. He is member of Chinese Academy of Sciences, fellow of The World Academy of Sciences for Advancement of Science in Developing Countries. He won several science awards, including China National Natural Science Prize in 2007, TWAS prize in Chemistry in 2012, Khwarizmi International Award in 2019, JSCC International Award in 2020, and Highly Cited Researcher in Chemistry (2014-2020).

Professor Chen's research is in the fields of coordination chemistry and crystal engineering of molecular solids, focusing on the synthesis, crystal structures and properties. He has made significant contributions to our understanding of rational design and properties of porous coordination polymers (PCPs) or metal-organic frameworks (MOFs), especially metal-azolate frameworks (MAFs) as a subclass of MOFs, including the creation of the most extensively used SOD-type zinc 2-methylimidazolate (MAF-4, also well-known as ZIF-8), as well as hydrothermal/solvothermal in-situ metal/ligand reactions and their applications.

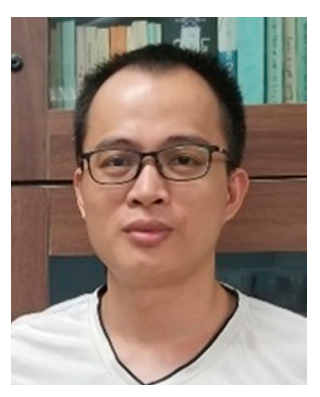

\section{Pei-Qin Liao}

Pei-Qin Liao was born in Guangdong, China, in 1988. He obtained his BSc in 2011 and PhD in 2016 under the supervision of Prof. X.-M. Chen and Prof. J.-P. Zhang at SYSU. After that, he joined the School of Chemistry of SYSU as an associate researcher in 2016, became an associate professor in 2018 and a professor in 2020. His current research interest is in the chemistry of metal-organic frameworks. 